\title{
National versus Regional, Many versus Few: The Dilemma Facing the Collection Societies
}

\author{
Phil Hardy \\ The View, music industry newsletter
}

Collection societies were created by authors, such as composers and lyricwriters who on their own could not turn their copyrights into money despite the fact that they were granted the legal right to authorise or prohibit other people's commercial use of their musical works. This was because individual authors could neither control nor keep track of how their music was used. Collection societies were set up to handle the right to perform copyright works to an audience, but when the market for recorded music emerged, the societies extended their reach to administer mechanical reproduction rights as well as performing rights. Because the societies from the beginning were monopolies, indeed had to be monopolies to work efficiently in the interests of both creators and users, they have always been carefully monitored and regulated. The story of the events that led to the creation of the French society SACEM bring all these elements together, creators (and publishers), users and a regulator (the courts).

In 1847 the French composer Bourget visited Les Ambassadeurs, a café in Paris, and ordered a glass of sugar water. While sipping this, he heard the string band of Les Ambassadeurs perform his composition Bluettes. No one had asked for his authorization of this and consequently he protested against this infringement of his copyright. An argument ensued and Bourget offered Les Ambassadeurs a settlement: if the club let him have his glass of water for free, the band would be allowed to play the song for free. Les Ambassadeurs turned down this reasonable offer and so it happened that parties met at the Tribunal de Commerce de la Seine. The court's decision of September 8, 1847 was in Bourget's favour and accordingly, backed by two other composers, Perizot and Henrion, and the music publisher Colombier, on February 28, 1851 he founded The Société des Auteurs, Compositeurs et Editeurs de Musique, SACEM. 
Between 1851 and the early twentieth century, composers and publishers founded national collection societies similar to SACEM in much of Europe and in North and South America. However, such societies were not generally established in Asia and Africa until the 1980s and 1990s, following the process of decolonisation.

For most of the twentieth century, the world of the collection societies was a stable one. The main purpose of this chapter is to show how that interlocking system of the nationally-based collective administration of copyrights was shattered, mostly by the actions of the collection societies themselves.

\section{National Societies and the Principle of Reciprocity}

As a preliminary to explaining that process, it is necessary to discuss the territorial basis of copyright and reciprocity. Copyright laws vary between countries, a reflection of the differing powers of users in different territories and of the different political priorities of the regulators. Thus, in both the U.S. and Japan the political influence of broadcasters has meant that the financial value of the rights of copyright owners has been smaller than in other comparably sized territories primarily because the performing right is more limited in scope than elsewhere. An example of the different priorities of different governments was the rejection in the 1980s by the UK government of a private copying levy on the basis that it would be a tax and an unnecessary intervention into the market economy, which the Conservative government of the time was generally opposed to.

Despite such differences, the principle of reciprocity has been the central feature of the relationships between the national collection societies. When his music is performed or recorded in his home country A, a composer receives royalties direct from his national society, which makes a small charge for the service. The principle of reciprocity ensures that the composer also receives payment when the same music is performed or recorded in foreign countries. Thus, the royalties for the use of his copyrights in countries B, C, D and so forth are collected by the relevant national societies, who, after deducting a charge for their services, remit the royalties collected in their territories to the national collection society of country $A$, which, again after making a deduction for its charges, sends on the royalties to the appropriate member.

This strictly national basis of copyright administration was directly challenged by the emergence of the "online" (Internet) market for music, which posed significant questions for the collective administration of copyright by raising the issue of the greater efficacy of regional (i.e. continent-wide) administration compared with nationally-based administration. But even before this development, the actions of 
the societies themselves had begun to undermine the stability of the system of reciprocity that they depended upon.

The cause of this threat to stability was the emergence in the 1980s of direct competition between the various national societies in Europe and the vehicle for this competition was known as a "central licensing agreement" (CLA).

\section{The Central Licensing Story}

\section{Record companies and CLA}

A central licensing agreement (CLA) is a contract under which an international record company undertakes to pay all the mechanical royalties due on soundcarriers (CDs, cassettes and vinyl records) sold in a large number of European countries to a single national society. In turn, the receiving society will pass on the royalties for soundcarriers sold in each country to the appropriate society. The CLA therefore largely replaces the nationally-based system of reciprocity already described.

The central licensing system was the result of the desire of large users of musical works, the major international record companies, to cut their costs and the determination of certain individual national collection societies to increase the flow of monies through their systems and thus reduce their own administration costs as a proportion of their total income.

The introduction of CLAs was made easier by the fact that there was already an industry-wide agreement setting a common pan-European mechanical royalty rate. This was the Standard Contract signed by the International Federation of the Phonographic Industry (IFPI), representing record companies and the International Bureau of Societies Administering the Rights of Mechanical Recording and Reproduction (BIEM), representing the continent's mechanical right collection societies.

CLAs now (in 2006) account for some 55 per cent of soundcarriers sold throughout Europe. At the present day, all four major international record companies have such licensing agreements. Currently the partners in the four CLAs are EMI and SDRM (the mechanical right collection society of France), Sony BMG and GEMA (the German society), Universal Music International (UMI) and SABAM (the Belgian society) and Warner Music Group (WMG) and GEMA.

These partnerships date from 2004 and came about only after fierce competition between national collection societies. Before that date SDRM (France), the mechanical right society linked to SACEM (France), had a CLA with Sony Music 
Europe (SME) and, through the Bureau Europèen des Licences (BEL), a joint venture with GEMA (Germany). The UK collection society (MCPS) was involved in a CLA with EMI. When that contract was not renewed last year, BEL was dissolved and SDRM (France) separately negotiated a new CLA with EMI. However, the creation of the Sony BMG record company led to the replacement of the SDRMSME deal with a CLA between Sony BMG and GEMA, previously the CLA partner of BMG. Meanwhile, UMI (in its former guise as PolyGram) had originally operated a CLA with Dutch society STEMRA, and then switched to the UK's MCPS before concluding its current CLA with SABAM (Belgium). These changes in CLA partnerships took place despite the fact that the costs of moving a CLA to a new national society partner are significant and that each change means a temporary disruption of the business of the user and its chosen society.

While the CLAs honoured the principle of reciprocity between national societies (in the distribution of royalties to individual authors and publishers), they dramatically eroded it at the same time. Societies competed for the business of the major record companies by offering those companies rebates on the amount of royalties payable. The rebates in effect meant that the society was reducing the revenues due to its members (and those of other societies). Each society was doing this in order to gain a possible reduction in administration costs but also greater influence within the society world, where a society's power is judged by the size of its turnover.

\section{Music publishers and CLA}

This was not all, for the principle of reciprocity was soon to be further eroded. But before explaining that development, it is necessary to understand the attitude of the major multinational music publishers to the emergence of CLAs and the general situation of collection societies. Ever since the formation of SACEM, publishers had been members of the societies, alongside the authors of musical works. They were entitled to receive a proportion of the royalties collected, although in continental Europe publishers as a whole received less than authors as a whole and in some national societies there were restrictions on the participation of publishers in decision making.

However, by the mid-twentieth century, the music publishing industry had undergone international consolidation in much the same way as the record industry so that it was dominated by a handful of large companies under the same ownership as the major international record companies. As well objecting to various society practices, ranging from social and cultural deductions to the lack of seats for music publishers on the boards of many of the societies, these very powerful music publishers decried the long delays (as they saw it) in the societies' transmission of royalties and (as they saw it) the disproportionate commissions 
taken by the societies on the royalties they collected and distributed. They naturally also objected to the rebates offered by societies in order to secure CLAs.

In 1996 after putting pressure on the societies to reform with little success, EMI Music Publishing (EMI MP) briefly withdrew the right to collect royalties for Simply Red's album "Life" from MCPS (UK). Instead, EMI MP would collect the mechanical royalties directly from Simply Red's record company Warner Music Europe through Mechanical Rights Society Europe (MRSE), a collection society it specifically set up for this purpose. EMI MP said it would take this action because of excessive delays in receiving monies through the GEMA-Warner Music Europe CLA, and because of the high rebate given by GEMA to WME.

In the event, the threat was withdrawn. But it was enough to cause Europe's largest collecting societies to seek ways to limit the costs of distributing mechanical royalties. At a series of meetings in 1996 the societies agreed that the cost of distributing mechanical royalties be regularised, with a commission rate of some 10 per cent for smaller societies and 8 per cent, or less, for the larger societies. The differing rates reflected the fact that, while the average cost of collection through CLAs had fallen, the costs of distribution varied widely, largely in proportion to the size of a society. Thus, while GEMA's distribution overheads were around 8 per cent of its revenues in 1996, those of societies in the smaller European nation states, to which GEMA remits money, were far higher.

This pressure on the societies was further intensified when towards the end of 1996 PolyGram announced that it would move its CLA from STEMRA (Netherlands) to MCPS (UK). As usual part of the deal was a rebate offered by MCPS to PolyGram. More contentiously, MCPS also offered to distribute directly mechanical royalties collected from PolyGram that were due to composers of any nationality represented by PolyGram Music Publishing, bypassing the other societies. A mark of how much this was seen as an attack on the principle of reciprocity was that in response SDRM (France) and GEMA (Germany) terminated their reciprocal arrangements with MCPS (UK) at the end of 1996 and STEMRA (Netherlands) and SIAE (Italy) gave notice that they would also end their reciprocal arrangements with MCPS.

\section{Cannes Accord}

Without going into much detail, the final result of these moves by music publishers, record companies and the societies was the signing in January 1997 of what is generally referred to as the Cannes Accord. Under this the European collection societies and the six major record company-owned publishers agreed that the societies would reduce their average commission rate for mechanical royalties from soundcarrier sales to 6 per cent by 2001. To achieve the average of 6 per cent, 
societies with smaller turnovers (such as those of Greece and Portugal) would bring rates down from 20 per cent to between 9 and 12 per cent while the larger societies, notably GEMA and SDRM, were required to reduce their rates to less than 6 per cent. The specialist newsletter Music \& Copyright (1997) estimated that music publishers' revenue from this source would be some $\$ 100$ million higher over the period covered by the Accord. The Cannes Accord also included an agreement that the direct distribution of phono-mechanical royalties by MCPS to PolyGram composers would not go ahead.

Other benefits of the Cannes Accord for the music publishers included speeding up the transmission of the monies from the societies to the publishers and their authors and guaranteed twice-yearly payments to publishers with advances set against each payment. Moreover, because the commission rate was a weighted average, the societies became subject to independent audits.

The Cannes Accord brought peace to the collection society and music publishing world, a peace that was extended when a Cannes Accord Extension was agreed in 2002. This imposed severe restrictions on the societies' ability to compete with each other by offering rebates to record companies in order to get their business. The Extension stated that, of the 6 per cent commission on mechanical royalties collected through a CLA, a rebate of two and a half percentage points would be given to the central licensor (i.e. the record company) and of the remaining three and half percentage points, 2.4 per cent would go to the distributing society in each country. This left the CLA collection society with a commission of only 1.1 per cent. With such a low margin, it would be very difficult for societies to attract new clients by increasing the rebate to record companies or by reducing the 1.1 per cent they retained to administer the deal - while at the same time complying with the terms of the Cannes Accord.

\section{Common Information System (CIS) and the IMJV}

These limiting factors led the larger societies to look at the possibility of cooperating rather than competing. They were already working together through CISAC, the International Confederation of Collecting Societies, to develop the socalled the Common Information System (CIS), which offered the collection societies the possibility of undertaking certain routine tasks once electronically, instead of manually many times.

The aim of CIS was to use a standard series of numbers (the International Standard Works Code or ISWC) to identify individual musical works and their owners in order to create a globally compatible virtual database of works. Each society would enter the details of its repertoire into the virtual central database of titles, thus eliminating the 
need for other societies to re-enter the information. However, although the long-term advantages of CIS were apparent, it quickly became clear that its implementation would entail significant costs and logistical problems for the societies. CISAC set up a Pioneer Group to speed up the implementation of CIS in 1998 but was only able to make it mandatory for societies to use CIS-based data in 2000.

This meant that, in 1998, the combination of the economies demanded by the Cannes Accord and the costs associated with CIS led to a situation in which the larger European (mechanical) collection societies found it harder to compete with each other to secure CLA deals and the smaller societies found it harder to fund their share of the implementation of CIS.

Paradoxically, this was seen as an opportunity by some societies to rekindle competition between collection societies in the guise of the International Music Joint Venture (IMJV). In 1998 three of the world's largest collecting societies established IMJV as a cost-saving venture for themselves, with part of the savings planned to come from selling the management of CIS and related back-office activities to other societies.

For a variety of societies, therefore, IMJV was intended to provide economies of scale, either as partners or clients. However, although the logic seemed compelling, many societies decided not to join IMJV for much more immediate and local reasons. For example, the USA performing right organisation BMI decided not to join because it considered that its computer system was as advanced as that being proposed by IMJV. On the other hand, the USA mechanical right organisation the Harry Fox Agency was not willing to make the necessary financial commitment to upgrading its computer systems.

With hindsight, it is also apparent that local concerns as much as longer-term strategies motivated the IMJV's founding partners. At the time they created IMJV, both the USA society ASCAP (BMI's rival) and the UK societies MCPS and PRS needed to upgrade their computer systems and both saw IMJV as a way of doing so with the added advantage of selling on the functions allowed by the upgrade to other (smaller) societies. The concerns of the third founder, BUMA-STEMRA of the Netherlands, were even more local. The Dutch mechanical society STEMRA, having lost its central licensing deal with PolyGram (just prior to PolyGram's becoming part of UMI, Universal Music International) needed to reduce costs but was unable under Dutch employment law to cut staff levels. It saw the IMJV as a way to redeploy staff. This explains why the IMJV headquarters was planned to be in Hoofddorp in the Netherlands.

As development of the IMJV proceeded, the tensions between the local concerns of the founder members and the larger concerns of the project grew. This 
was particularly noticeable during the period in which the IMJV courted GEMA as a possible member. As one of the largest European societies, GEMA was faced with making the greatest cost-savings to achieve the 6 per cent weighted European commission rate. Accordingly, IMJV initially looked attractive to GEMA. However, after a lengthy examination of IMJV, GEMA decided not to join. Some of the reasons were local. GEMA was unwilling to reduce its own staff levels so that STEMRA would not have to, and was concerned that it would lose contact with its members who would need to address any queries to Hoofddorp rather than a local German office.

The need for IMJV's operations to be centralised worried Europe's large societies which had become increasingly protective about their national repertoire of musical works. For many, the location of IMJV in the Netherlands implied losing control of their data (and by implication their repertoire) with a consequent diminution in status. A further problem was that over the years it had become apparent that the integration of databases would not be as straightforward as initially envisaged by the IMJV. This had already been proven in the case of NORD- DOC, the joint Nordic works documentation and registration system, which, although eventually successful, was far more difficult to create than expected. Moreover, whereas NORD-DOC was created as a virtual database wholly within the society system, IMJV was seen by some as a threat to the society system.

In particular, a number of the societies of smaller nations felt threatened by the IMJV. They saw their own disappearance as an inevitable consequence of IMJV and its proposed solutions to the problems of reducing costs. That concern was increased when the efficiencies being claimed by IMJV were hard to substantiate. For example, MCPS-PRS claimed at one time that the creation of the IMJV would cut the average administration costs of PRS to 10 per cent and of MCPS to 4 per cent. However, the integration of the databases of MCPS and PRS, which was required to create a platform for the subsequent creation of the IMJV database, proved to be far more problematic than expected and the saving far less.

IMJV's business plan had envisaged a return on investment of about 30 per cent, with the profits being used not only to defray the costs incurred by the joint venture's members, but also to give a return on investment for any private sector investor. This was highly significant because never before had there been a profit element in inter-society dealings. IMJV was also ambitiously hoping that it would later be able to undertake transaction switching and then real-time licensing and to offer its services to music publishers as well as to societies.

However, none of this was to occur because in January 2002 the IMJV announced that it no longer intended to open its centre in the Netherlands. At a time when most societies were forecasting a decline in mechanical collections in the coming years, the partners were unwilling to invest more money in the project. 


\section{Common Information System and FastTrack}

Although the IMJV idea was now dead, it was not the only response to the problems posed by the implementation of CIS. Another consortium of collection societies, known as FastTrack, whose aim was to implement CIS, arose out of the realisation that CISAC was in need of reform.

Founded in 1926 as a confederation of national authors' societies, by the mid1960s CISAC had grown into a large, well-funded institution that was midway between an international trade association and a non-governmental lobbying organisation. As such it became highly bureaucratic, with several layers of administration. This process was further accelerated in the 1980s and 1990s as the cultural and commercial importance of intellectual property and its administration spread, requiring the formation of new national societies and the provision of assistance to small and undeveloped societies especially in Eastern Europe, Africa and Asia. CISAC saw its function as assisting these new societies.

By the late 1990s, the continuing pressure on the larger European societies to cut costs highlighted the significant amounts of money that were spent, often in inappropriate ways according to some, on CISAC's administration. These costs were in the main paid by the larger societies, which increasingly sought ways to restrain and audit CISAC's expenditure and to ensure that it prioritised the implementation of CIS and other projects related to the digital environment.

For these societies in particular, CIS promised to provide a way of contributing to the administrative savings required by the Cannes Accord through its greater efficiency in the registration of musical works, the exchange of that information between societies and the facilitation of (speedier) royalty payments. Hence it was those societies that most enthusiastically supported the possibilities that ISWC and CIS offered the CISAC membership.

CIS had been adopted as a goal by CISAC in 1995 but its cumbersome administrative structure had proved to be ill-equipped to bring the programme to fruition and the introduction of CIS was delayed several times. Subsequently, the larger societies were partially successful in reforming CISAC and at the CISAC Congress in Chile in 2000 it was reported that the creation of a group of ten societies to steer the implementation of CIS had resulted in the establishment of a streamlined CIS project for musical works only. Finally, in 2004, CISAC handed over to the FastTrack organisation the implementation and administration of CIS.

FastTrack was formed in 2000 by a group of societies that, for a variety of reasons, had not joined IMJV, but continued to have doubts about CISAC's ability to see CIS through to a successful conclusion. In contrast to IMJV, FastTrack was 
to be a network solution to the opportunities and problems posed by CIS. FastTrack planned to link the databases of U.S. collection agency BMI, France's SACEM, Germany's GEMA, Spain's SGAE and Italy's SIAE through the Internet. To do this each member society would create a clone of its database which member societies could then access, search, and raise questions about, and to which members could supply ancillary information. It was hoped that in this way data registration problems would be speedily eliminated.

Furthermore FastTrack would not require member societies to give up control of the administration of their repertoire. It would also be significantly cheaper to implement than IMJV, because it was essentially a secure Internet link between the member societies' existing databases, and as such did not acquire any additional staff.

The first phase of FastTrack cost some $\$ 3 \mathrm{~m}$ compared to the $\$ 20 \mathrm{~m}$ that IMJV had set aside for start-up costs. Initially FastTrack's aims were more limited than IMJV's. It did not propose to offer third party back office solutions, and from the start its reliance on networking rather than the creation of a centralised service was attractive to other societies. Whereas the territories represented by the IMJV members generated a little over 20 per cent of world music publishing revenues, the revenues of the territories represented by the original FastTrack societies were twice that amount. This percentage continued to rise as other societies joined the new venture. In 2001 AKM/Austro-Mechana (Austria), SABAM (Belgium) and SUISA (Switzerland) joined FastTrack, and in 2003 two of the founder members of IMJV, MCPS-PRS and BUMA-STEMRA joined, as did Canada's SOCAN, which had been a later member of IMJV. Finally, in March 2004 the third founding member of IMJV, ASCAP (USA), joined FastTrack.

As more societies joined, CISAC chose to hand over the organisation and implementation of CIS to FastTrack. In January 2004, the Executive Bureau of CISAC and the Supervisory Board of FastTrack signed an agreement to adopt the FastTrack software, systems and data protocols as the basis of the next stage of CIS, CIS-Net. Later the same year CISAC formally announced that it would make the use of CIS-Net mandatory for its 209 member societies.

It remains to be seen whether the attempt to reposition CISAC as a more professional, cost-conscious and technical body will be successful. One mark of the success or otherwise of these changes, a test that CISAC has failed in the past, will be the ability of CISAC to enforce the use of CIS-Net by its member societies. At this point, it seemed that, after a lengthy series of wars of attrition, something like harmony had broken out in the collection society world. Such hopes were soon dashed by new disputes focused on European licensing issues. 


\section{Enter the European Commission}

The first of these again concerned central licensing agreements. Although the Cannes Extension Agreement (CEA) had made it difficult for societies to compete for CLAs, some continued to do so and when MCPS refused to offer UMI (Universal Music International) a rebate in negotiations to extend an existing CLA, in 2003 UMI filed a complaint against MCPS with the European Commission Competition Authority. $\mathrm{UMI}$ interpreted the decision by MCPS to withdraw its rebate as a consequence of the restrictions placed on the actions of collection societies by the CEA. Earlier in the same year, UMI had filed another complaint at the European Commission, seeking a ruling that the pan-European mechanical royalty rate set out in the Standard Contract between IFPI and BIEM was too high and was anti-competitive.

The factors affecting European mechanical societies had changed since the implementation of the Cannes Agreement (CA) and its Extension Agreement (CEA). Whereas in the 1990s there were incentives for the societies to compete against each for CLAs, now the main incentive was for them to work together to reach cost saving targets and to satisfy the new demands (such as lower administration rates and greater transparency of accounting) being placed upon them by both their composer and publisher members. Moreover, at a time of a decline in the amount paid in European mechanical royalties (a direct consequence of falling recorded music sales), securing CLAs was no longer as attractive to societies, because of the costs involved, and the benefits of such deals were less clear.

The complaints by UMI were an additional challenge to the principle of reciprocity, already undermined by the actions of the societies in the offline world. This assault on the societies was extended to the online world by the European Commission itself in 2005, when it proposed significant changes to the system of authors' rights management by national collection societies. In order to remove obstacles to the growth of the online music market, the EC wanted to introduce a system whereby any national society could offer a pan-European licence for online uses of music and a composer could join any society irrespective of his place of residence or nationality.

The EC proposal was made in a staff working document entitled "Study on a Community Initiative on the Cross-Border Collective Management of Copyright". In the study the EC outlined three different options for online licensing. These were:

1. To retain the current system of reciprocal agreements between national societies

2. To modify that system 
3. To introduce a new scheme whereby rights' owners can authorise a single society to manage the online uses of their works throughout the European Union (EU).

The EC rejected Options 1 and 2, because the present arrangements require an online music company (intending to operate throughout the $\mathrm{EU}$ ) having to seek up to 25 separate national licences. The EC concluded that the only viable solution was Option 3, which it foresaw would lead to the emergence of a few powerful societies for online licensing. These in turn would effectively defend authors' interests vis-àvis commercial users at the pan-European level.

The EC's view was that a reduction in the number of what it terms "collective rights managers" or CRMs was a price worth paying for the more efficient administration of cross border rights, improvements which the EC saw as the central requirement for the emergence of a sizeable and commercially viable European online music market. The starting point of the EC study was the significant difference between the size of the USA and European online music markets. The EC report noted that the retail value of online European recorded music sales in 2004 was $€ 27.2$ million ( $\$ 49.5$ million), but the retail value of U.S. sales was 130 per cent greater, at $\$ 113.8$ million. In contrast, according to IFPI, the retail value of offline soundcarrier sales in the U.S., at $\$ 12.85 \mathrm{bn}$, was only 4 per cent greater than that of Europe, at $\$ 12.35 \mathrm{bn}$. The EC study claimed that the gap between the European and USA online markets was the result of the greater obstacles to rights clearance and rights management facing would-be online music stores in the EU.

The EC's plans were welcomed by some collection societies who foresaw that they would be among the few societies empowered by the developments the EC proposals are intended to foster. Indeed, in the conclusion of the EC's study the authors noted that, while the study is directly concerned with the online music market, "We believe that Option 3 will also be the most sustainable long-term model" for the cross border distribution of offline royalties. In effect, if Option 3 were to be implemented it would bring about a complete restructuring of the collective administration of music copyrights throughout the EU. This would most likely entail the closure of many smaller societies, or at the very least a significant reduction of their activities, with a few large societies carrying out administration on their behalf.

Ironically the EC study also offers evidence that even in the offline world the principles of reciprocity were already more sinned against than championed by the collection societies themselves. Using information compiled by the analysts Cap Gemini, the EC report notes that there "is no commensurate relation between non-domestic repertoire exploited in a particular Member State and the transfer of royalties to non-domestic right-holders". Thus, although foreign repertoire accounted for between 55 and 62 per cent of music works exploited in Spain 
in 2004, the royalties distributed by Spanish authors' society SGAE to foreign collection societies was less than 12 per cent of its total collections. At the same time, according to the Cap Gemini study, the royalties paid to foreign societies by four large European societies (GEMA, SACEM, SGAE and SIAE) have grown at lower rates than their general rates of growth and that in 2003 of the $€ 4.9 \mathrm{bn}$ ( $\$ 5.5 \mathrm{bn})$ collected by European collection societies, $€ 3.8 \mathrm{bn}(\$ 4.7 \mathrm{bn})$ was distributed to authors and publishers, of which only 13.3 per cent ( $€ 506 \mathrm{~m}, \$ 624.7$ million) went to foreign copyright owners.

\section{Conclusion}

This chapter has presented the various ways in which the principle of reciprocity between national collection societies has come under attack from various directions in the past two decades. ${ }^{1}$ The forces undermining the reciprocity system have included users (the major international record companies) and creators' representatives (music publishing companies) whose own activities are global and transnational in scope. The third force working to the same effect has been the regulator in the form of the European Commission, committed to a pan-European free market in intellectual property. Last, but not least, the national societies themselves have been undoing their working principles. The societies have begun to negate their own system of reciprocity both in competing with one another for Central Licensing Agreements and in co-operating to create the Common Information System, which has the potential to make separate national repertoire databases redundant. Consequently, in the case of Europe in particular it seems that the regional rather than the national territory is about to become the basis of the new world facing the collection societies.

1 Following the period documented in this article, the European Commission upheld a complaint about music licensing by the pan-European broadcaster RTL. It would take a further essay to elucidate the EC adjudication, the responses to it by the collection societies, the subsequent recommendations of the EC concerning the administration of digital music rights within the European Community and the response of music publishers and societies to those recommendations. That said, this article indicates the continuing paths of development brought about by the increased focus on copyright administration in the current era. 


\section{References}

"Publishers to gain over $\$ 100 \mathrm{~m}$ from new Euro mechanical deal", Music \& Copyright 106, January 1997, 1. 